\title{
Estudo retrospectivo de fimose traumática em equinos e tratamento utilizando a técnica de circuncisão com encurtamento de pênis (1982-2007)
}

\author{
Retrospective study of traumatic phimosis in horses and treatment with penis shortening \\ surgery circumcision (1982-2007)
}

\author{
Luiz Antonio Franco da Silva ${ }^{{ }^{*}}$ Rogério Elias Rabelo ${ }^{\text {II }}$ Roberta Ferro de Godoy ${ }^{\text {III }}$ \\ Olízio Claudino da Silva ${ }^{\mathrm{I}}$ Leandro Guimarães Franco ${ }^{\mathrm{I}}$ Cássia Maria Molinaro Coelho ${ }^{\mathrm{I}}$ \\ Leonardo Lamaro Cardoso ${ }^{I}$
}

\section{RESUMO}

Traumatismos no pênis e prepúcio de garanhões são causas comuns de infertilidade nos equinos e entre elas destaca-se a fimose, que, neste estudo retrospectivo, realizado em 367 propriedades rurais, foram encontrados 49 casos da enfermidade, sendo 43 casos de origem traumática e com 12 óbitos. A técnica de circuncisão com encurtamento do pênis foi utilizada para a correção da enfermidade em 20 animais, distribuídos em dois grupos de acordo com o protocolo anestésico utilizado. Todos os equinos apresentaram como complicação pós-operatória edema em vários graus, porém diminuindo significativamente em 95\% dos animais após o sétimo dia. Assim, concluiu-se que a técnica de circuncisão com encurtamento peniano constitui-se em alternativa viável e eficiente no tratamento de fimose traumática em equinos.

Palavras-chave: fimose, prepúcio, equino.

\section{ABSTRACT}

Penis and prepuce injuries of stallions are common causes of infertility in horses and among them, paraphimosis is featured. This retrospective study was conducted in 367 rural properties and 49 cases were found; 43 of them were traumatic with 12 deaths. The technique of circumcision with shortening of the penis was used for the correction of the disease in 20 animals. They were divided into two groups according to the anesthetic protocol used. All horses had post-operative complications such as edema in various degrees, which decreased significantly in 95\% of animals after the seventh day. Thus, it was concluded that the technique of circumcision with penis shortening is an effective alternative in the treatment of traumatic paraphimosis in horses.

Key words: phimosis, prepuce, equine.

\section{INTRODUÇÃO}

O pênis do equino é classificado como musculocavernoso e pode ser anatomicamente dividido em base, corpo e glande. A glande e o corpo são envolvidos pelo prepúcio quando em repouso. $\mathrm{O}$ prepúcio apresenta um dobramento duplo de pele, lâmina externa e interna, possuindo ainda uma prega prepucial interna. No óstio prepucial, a pele, ou lâmina externa, transforma-se na cavidade prepucial, que segue caudalmente como lâmina interna, para, finalmente voltar-se envolvendo o pênis. O prepúcio pode ser movimentado pelos músculos prepuciais, que se originam no músculo cutâneo (LITTLE \& HOLYOAK, 1992; CERVENY et al., 2004).

A ocorrência de traumas envolvendo o pênis e prepúcio são causas comuns de infertilidade em garanhões (MACKINNON \& VOSS, 1992). Os traumatismos produzidos na genitália externa são considerados uma condição de risco para os garanhões e devem ser tratadas como emergência a fim de se evitar danos à espermatogênese, à habilidade de realização da cópula e em especial à ejaculação do animal (PERKINS \& FRAZER, 1994). As lesões traumáticas podem interromper uma estação de monta ou diminuir a eficiência reprodutiva do plantel, justificando a importância econômica do problema (PAPA \& LEME, 2002). As causas mais freqüentes de lesões prepuciais

IEscola de Veterinária, Universidade Federal de Goiás (UFG), Campus II, CP 131, 74001-970, Goiânia, GO, Brasil. E-mail: lafranco@vet.ufg.br.*Autor para correspondência.

IEscola de Veterinária, UFG, Campus Avançado Jataí, Jatái, GO, Brasil.

IIIFaculdade de Agronomia e Medicina Veterinária, Universidade de Brasília (UnB), Brasília, DF, Brasil. 
incluem coices de éguas durante o cortejo sexual, abrasão por pêlos da cauda, briga com outros equinos e traumatismos provocados por cercas, principalmente quando o pênis encontra-se ereto (SCHUMACHER \& VAUGHAN, 1988; GATEWOOD et al., 1989; PERKINS \& FRAZER, 1994).

Dentre as enfermidades que comprometem o aparelho reprodutor do equino, a fimose caracterizase pela estenose do óstio prepucial e impossibilidade dos animais em exteriorizar o pênis. A alteração pode ser congênita ou adquirida em conseqüência de hematomas, neoplasias, granulomas, infecções e traumatismos, podendo causar retenção de urina com formação de processos inflamatórios na mucosa prepúcial (SCHUMACHER \& VAUGHAN, 1988; MEDEIROS et al., 1997).

O tratamento da fimose visa promover o retorno da configuração anatômica do prepúcio e a terapia medicamentosa com corticóides deve ser tentada antes da intervenção cirúrgica, principalmente quando se tratar de garanhões, pois o ato cirúrgico pode alterar a eficiência reprodutiva do animal (GATEWOOD et al., 1989). A técnica de circuncisão com encurtamento do pênis é indicada na preparação de rufiões equinos, remoção de neoplasias, granulomas e excesso de tecido cicatricial como em fimoses (TURNER \& MCILWRAITH, 1985; MAIR et al., 2000). Esta técnica apresenta um período de intervenção curto, poucos planos anatômicos atingidos, fácil reconstrução da ferida cirúrgica, além de poder ser realizada a campo (SILVA et al., 1995). Entretanto, apesar da fimose traumática em equinos ser um assunto relativamente descrito na literatura, são poucas as abordagens, relacionadas a etiopatogenia do processo, procedimentos cirúrgicos e condutas adotadas no pósoperatório.

O objetivo desse estudo foi avaliar aspectos epidemiológicos da enfermidade e propor a utilização da técnica de circuncisão com encurtamento do pênis, analisando sua viabilidade no tratamento de fimose traumática em equinos.

\section{MATERIAL E MÉTODOS}

O estudo foi realizado no Estado de Goiás, Brasil, em 367 propriedades rurais e no Hospital Veterinário da Universidade Federal de Goiás (HV/UFG), no período de 1982 a 2007, utilizando uma população de 5128 equinos do sexo masculino, de diferentes idades, raças, castrados e não castrados. Os atendimentos foram realizados por ocasião de aulas práticas ministradas em propriedades rurais, desenvolvimento de projetos de extensão e pesquisa ou mediante solicitação dos proprietários. Para se avaliar a ocorrência de fimose e aspectos envolvidos na etiopatogenia da enfermidade, foi elaborado um questionário fechado, cujas indagações principais eram direcionadas para o número de equinos do sexo masculino existentes na propriedade, distribuição por faixa etária, situação reprodutiva, comportamento do animal enfermo, manejo, presença de lesões no prepúcio, pênis e escroto, protocolos terapêuticos empregados, destino dos animais enfermos e ocorrência de casos similares em outras ocasiões.

Após o diagnostico clínico (MEDEIROS et al., 1997), 20 equinos portadores de fimose traumática foram selecionados e distribuídos em dois grupos (GI e GII) de dez animais cada, de acordo com o local onde foi realizado o tratamento. No grupo GI, foram alocados equinos operados a campo, com protocolo de anestesia intravenosa total e no grupo GII alocados os equinos operados no Centro Cirúrgico de Grandes Animais da HV/UFG, empregando anestesia inalatória. Outros 29 casos de fimose traumática relatados na pesquisa foram alocados no grupo GIII e utilizados apenas para o estudo epidemiológico. Portanto, computou-se um total de 49 animais portadores do problema durante o estudo.

A técnica preconizada para a correção da enfermidade dos equinos pertencentes aos grupos GI e GII foi a circuncisão com encurtamento peniano (SILVA et al., 1995) e modificada nesse estudo para a correção do problema. No pré-operatório os animais receberam soro antitetânico (Vencofarma, LondrinaPR), via subcutânea (SC) e foram submetidos a jejum hídrico e alimentar de 12 horas. O protocolo anestésico utilizado nos equinos distribuídos no grupo GI foi 0,1mg $\mathrm{kg}^{-1}$ de acepromazima (Acepran ${ }^{\circledR}$, Univet, São Paulo$\mathrm{SP})$, por via intramuscular (IM) como medicação préanestésica (MPA) e indução com $0,1 \mathrm{mg} \mathrm{kg}^{-1}$ de diazepam (Compaz ${ }^{\circledR}$, Cristália, Itapira-SP), associado a 2,2mg kg-1 de cetamina (Ketamina Agener ${ }^{\circledR}$, Agener União, Embu-Guaçu-SP), administrados por via intravenosa (IV). A manutenção foi realizada por infusão contínua de $100 \mathrm{mg} \mathrm{kg}^{-1} \mathrm{~h}^{-1}$ de éter gliceril guaiacol a 5\% (Henrifarma, São Paulo-SP) associado a $4,0 \mathrm{mg} \mathrm{kg}^{-1}$ $\mathrm{h}^{-1}$ de cetamina e $1,0 \mathrm{mg} \mathrm{kg}^{-1} \mathrm{~h}^{-1}$ de xilazina (Sedomin ${ }^{\circledR}$, Konig, Santana de Parnaíba-SP), diluídos em solução fisiológica a 0,9\% (JP Indústria Farmacêutica S.A, São Paulo-SP). Nos animais pertencentes ao grupo GII a MPA e indução foi a mesma sendo a manutenção anestésica realizada com halotano (Tanohalo ${ }^{\circledR}$, Cristália, Itapira-SP). A anti-sepsia nos animais pertencentes a ambos os grupos foi realizada mediante limpeza do campo cirúrgico com água e sabão e aplicação de iodopovidona (Farmogral, Brasília-DF). 
A correção cirúrgica da fimose utilizando a técnica de circuncisão com encurtamento do pênis foi constituída de quatro tempos operatórios. Primeiro, realizou-se a abertura cranial do óstio prepucial ocluído, removendo-se por meio de dissecação com tesoura romba o tecido conjuntivo e a fibrose cicatricial, presentes no local, até a localização e exteriorização da porção livre do pênis. Na manobra cirúrgica seguinte, o tecido epitelial de revestimento peniano foi demarcado utilizando quatro pinças de Allis, eqüidistantes, sendo uma dorsal, uma ventral e duas laterais, distando aproximadamente quatro centímetros da coroa da glande. O tecido epitelial de revestimento peniano foi incisado de pinça a pinça, circundando a área delimitada, evitando a formação de ângulos na intersecção das mesmas. O terceiro tempo cirúrgico constitui-se de uma incisão longitudinal, partindo da borda da ferida decorrente da circuncisão até a região limítrofe com a lâmina interna da prega prepucial externa, que também foi descolada e removida por meio de dissecção romba. Após a remoção das duas estruturas, deixando visualizar o tecido sub-eptelial que envolve a porção livre do pênis e o localizado sob a lâmina interna do prepúcio, os vasos seccionados foram pinçados e ligados com categute simples 2-0 (Medline, Goiânia-
GO). A conclusão desse tempo operatório consistiu na aproximação e fixação do corpo peniano, a partir da base da sua porção livre, à face interna do folheto prepucial externo, empregando-se fio de náilon 0 (Medline, Goiânia-GO), em sutura padrão simples separado. O conjunto de manobras realizadas no decorrer desse tempo operatório representou a principal modificação da técnica cirúrgica de circuncisão com encurtamento do pênis. Finalmente, foram realizadas quatro incisões longitudinais, de aproximadamente 1,5 centímetros e eqüidistantes às pinças, na borda do tecido epitelial de revestimento da porção caudal do pênis, para facilitar a sua coaptação à borda do óstio prepucial neoformado. Para aproximação do tecido localizado no ponto de correspondência das pinças realizou-se sutura tipo Donatti com fio de náilon número 0 . O fechamento completo da ferida foi realizado com o mesmo fio em padrão de sutura simples separado, evitando a formação de dobras e deixando a glande exteriorizada (Figuras 1 e 2). Todos os animais inteiros foram orquiectomizados.

O pós-operatório estabelecido para os equinos constou da aplicação de uma associação de penicilinas (Septipen Plus ${ }^{\circledR}$, Vallée, Montes Claros-

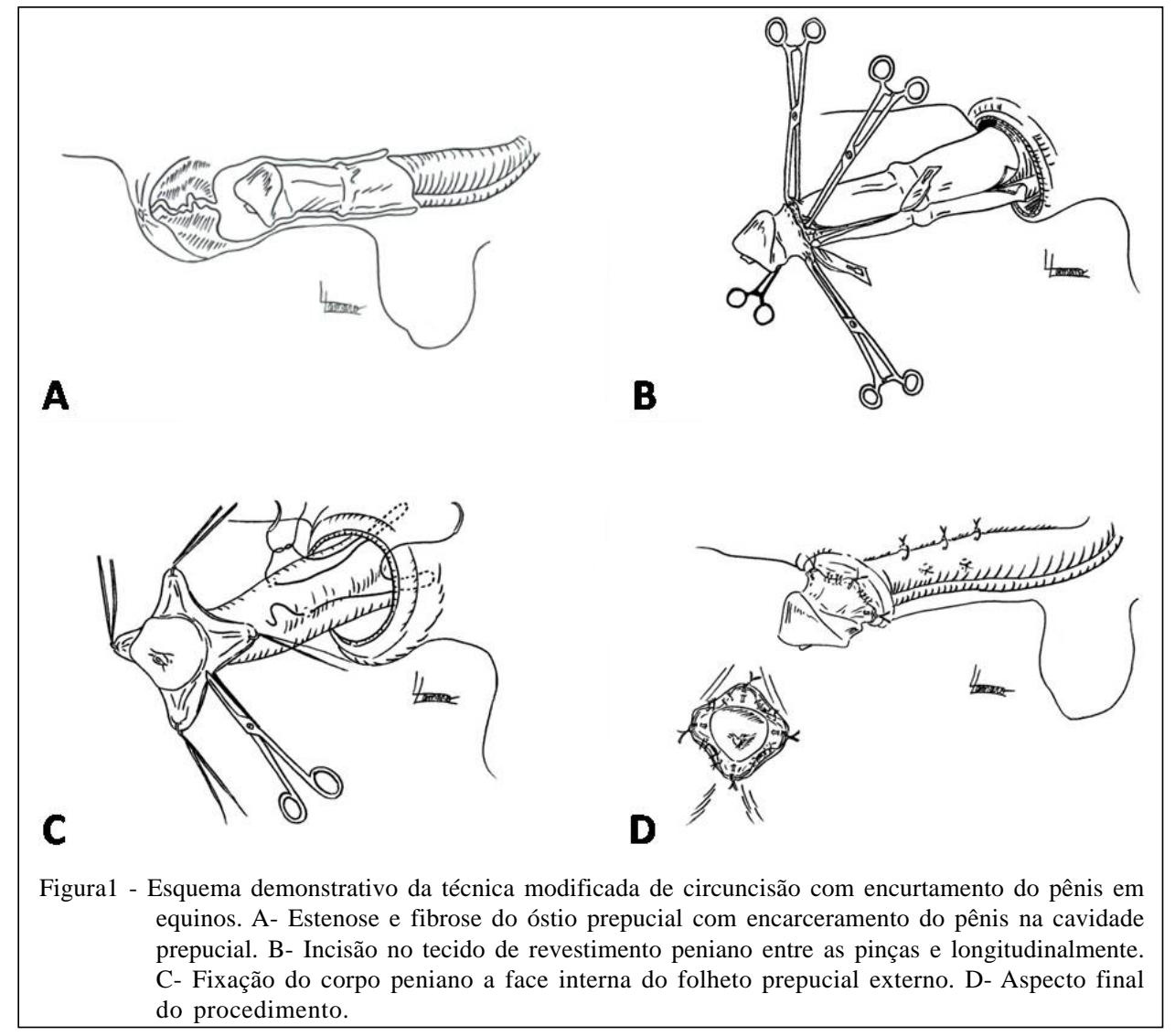




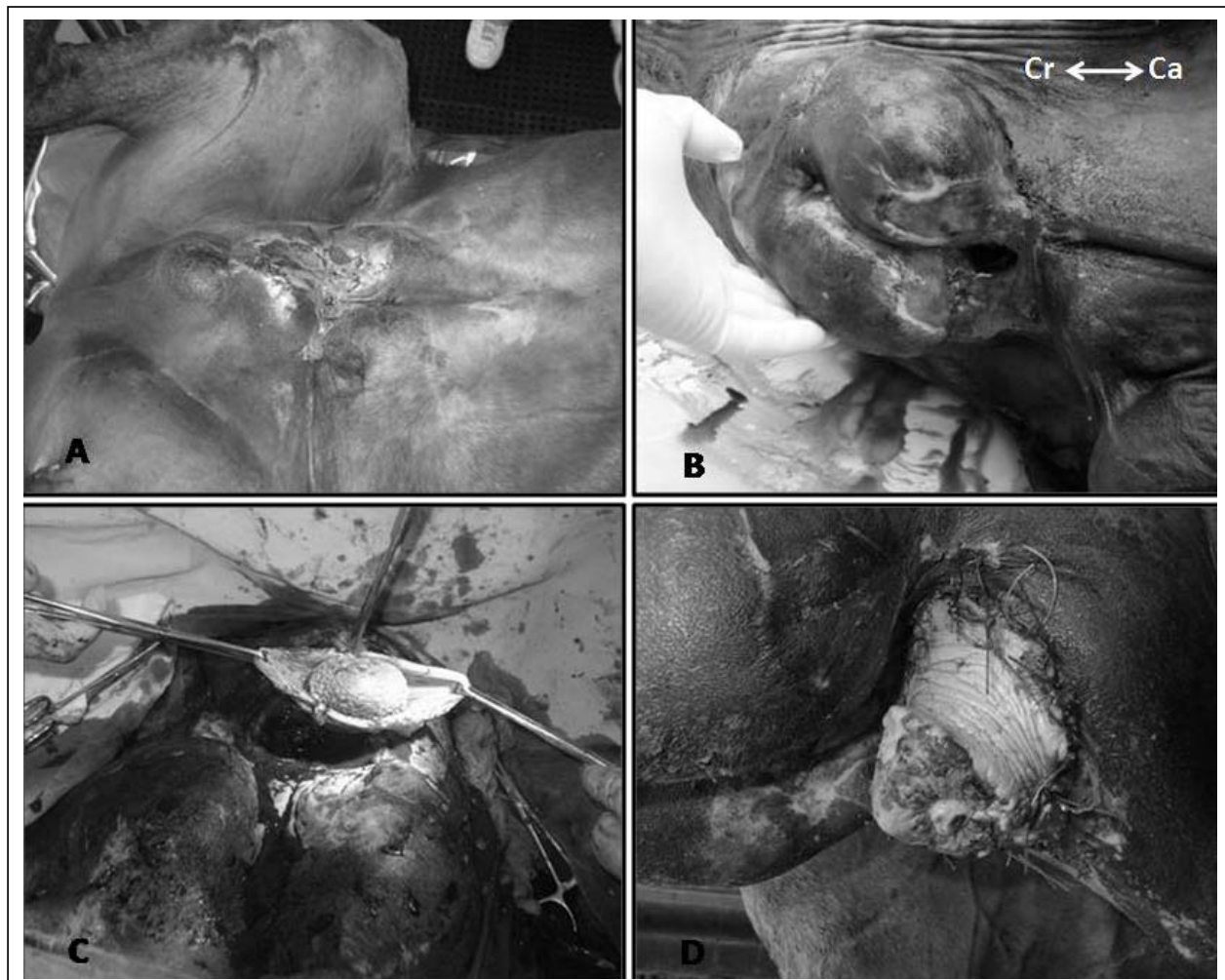

Figura 2 - Fimose traumática em equinos. A - Destruição parcial do prepúcio. B- Destruição parcial do prepúcio acompanhado de retenção urinária. C-Demarcação do tecido epitelial de revestimento peniano com pinças de Allis. D-Aspecto final da ferida cirúrgica.

MG), na dose de $20000 \mathrm{UI} \mathrm{kg}^{-1}$, IM, a cada 48 horas até completar três aplicações e $1,1 \mathrm{mg} \mathrm{kg}^{-1}$ de flunixim meglumine (Banamine ${ }^{\circledR}$, Schering-Plough-Cotia-SP), IM, diariamente, por três dias consecutivos. A ferida cirúrgica foi higienizada diariamente com uma solução a 3:100 de iodophor (Biocid ${ }^{\circledR}$, Pfizer, Guarulhos - SP) e aplicação de pomada a base de penicilina (Ganadol ${ }^{\circledR}$, Fort Dodge, Campinas-SP) até a completa cicatrização clínica. Esse mesmo protocolo foi empregado no escroto após a orquiectomia. A remoção dos pontos foi praticada entre o $12^{\circ}$ e $13^{\circ}$ dia do pós-operatório iniciando-se de forma alternada e considerando sempre a reparação clínica da ferida. Nos locais onde a cicatrização clínica não havia se completado, os pontos de Donatti foram mantidos por mais três dias. A evolução clínica das feridas dos animais que constituíram os dois grupos foi avaliada anotando-se a presença de possíveis casos de edema, deiscência parcial ou total da ferida cirúrgica, desenvolvimento de abscesso e recidivas. O edema foi classificado em discreto quando o aumento de volume localizava-se apenas no prepúcio, moderado quando atingia o prepúcio e escroto e intenso nos casos em que o aumento de volume se estendia até a região ventral do abdome.
Os dados obtidos foram analisados descritivamente de acordo com SAMPAIO (2002).

\section{RESULTADOS E DISCUSSÃO}

De um universo de 5128 equinos do sexo masculino existentes nas 367 propriedades atendidas, 3995 (77,9\%) eram castrados e 1133 (22,1\%) não castrados. Quanto à faixa etária, 1321 (25,8\%) possuíam até cinco anos, $2786(54,4 \%)$ entre cinco e dez anos, 907 (17,6\%) entre dez e quinze anos e 114 (2,2\%) acima de quinze anos de idade. Acrescente-se que 4009 (78,2\%) eram manejados extensivamente, 848 (16,5\%) em regime semi-extensivo e 271 (5,3\%) manejados intensivamente. Os dados obtidos após aplicação dos questionários apontaram seqüencialmente e em ordem decrescente de ocorrência, o prepúcio, seguido pelo pênis e escroto como os principais locais de lesões adquiridas na genitália de equinos, sendo os tumores, habronemose, pitiose, hérnia inguinal, parafimose e fimose os achados de maior ocorrência.

Quanto aos 49 casos de fimose traumática considerados no presente estudo, incluindo os 20 equinos submetidos ao tratamento cirúrgico (Grupos I 
e II) e 29 animais cujo problema ocorreu em períodos sem acompanhamento de um profissional do estudo (GIII) foi possível resgatar informações, as quais indicam que em 43 animais $(87,8 \%)$ a enfermidade iniciou-se após traumatismo na genitália provocado por arame, objetos perfurantes ou coices de outros animais, especialmente fêmeas durante o cortejo sexual. Estes achados encontram sustentação nos trabalhos de MEMON et al. (1987), SCHUMACHER \& VAUGHAN (1988), PERKINS \& FRAZER (1994) e MEDEIROS et al. (1997), que também os apontaram como fatores desencadeantes do problema, ressaltando que a maior freqüência dos traumas no pênis e prepúcio ocorre por ocasião da estação de monta, principalmente quando se adota a monta natural. Os autores acrescentaram que outras lesões prepuciais podem participar da etiopatogenia do processo, confirmando as informações obtidas no presente estudo, já que em três $(6,1 \%)$ animais, antecedendo ao diagnóstico de fimose houve relato da ocorrência de habronemose cutânea e em três $(6,1 \%)$ o problema ocorreu após exérese de massa tumoral. Como ambas as enfermidades localizavam-se na região do óstio prepucial, deduz-se que contaminações das feridas durante o pósoperatório e reação cicatricial exacerbada no local da intervenção cirúrgica possam ter propiciado o desenvolvimento da estenose do óstio prepucial e, conseqüentemente a fimose.

Dentre as 367(100\%) propriedades catalogadas nesse estudo, o problema ocorreu ou foi diagnosticado por ocasião das visitas em 49 (13,3\%). Destas, em 24 (49\%) os proprietários recorreram à assistência técnica especializada para tratar a enfermidade, 21 (42\%) utilizaram algum tratamento clínico, mas sem obedecer a orientação técnica e quatro (9\%) propriedades não utilizaram qualquer protocolo terapêutico, deixando o processo evoluir até o óbito dos animais.

Em relação aos 29 (100\%) equinos alocados no grupo GIII cujo problema foi diagnosticado em outras ocasiões, quatro $(13,8 \%)$ foram submetidos a tratamento cirúrgico, 13 (44,8\%) descartados e em 12 $(41,4 \%)$ o processo evoluiu para o óbito, apesar das inúmeras tentativas em solucionar o problema empregando alguns tratamentos sem orientação clínica. Possivelmente a retenção urinária, produção de endotoxinas e a dificuldade dos equinos se locomoverem contribuíram para a morte desses animais. Segundo MEDEIROS et al. (1997) a fimose pode ocasionar retenção de urina na cavidade prepucial com inflamação na mucosa prepucial, sem no entanto apontarem o óbito como uma das complicações da enfermidade.
Quanto aos protocolos anestésicos empregados nos 20 equinos portadores de fimose traumática e submetidos ao tratamento cirúrgico utilizando a técnica de circuncisão com encurtamento do pênis, tanto para os animais operados a campo (GI) como no centro cirúrgico do HV/UFG (GII) permitiram a realização, com segurança, dos procedimentos cirúrgicos sem observar qualquer intercorrência durante o trans-operatório. A conduta aqui adotada encontra-se respaldada nos trabalhos de MEMON et al.(1987), WALDRIDGE \& GILLIS, (1996) e MEDEIROS et al. (1997) os quais afirmaram que a correção cirúrgica de fimose e outras enfermidades prepuciais e penianas em equinos requerem protocolos de anestesia geral, seja intravenosa total ou inalatória. Os autores argumentam que a anestesia geral proporciona maior conforto para o animal e cirurgião e, possibilita a realização dos procedimentos cirúrgicos com o mínimo de intercorrências.

A divisão da técnica de circuncisão com encurtamento do pênis, em quatro tempos operatórios, preconizada por SILVA et al. (1995) e empregada nos animais distribuídos nos grupos GI e GII, fundamentouse na seqüência de manobras estabelecidas, conduta que permitiu a realização dos procedimentos cirúrgicos de forma ordenada, evitando-se inversão de manobras e conseqüentemente o comprometimento do resultado final. A conduta adotada ainda facilitou a localização da porção livre do pênis e sua posterior preparação para fixação no tecido localizado na face interna do folheto prepucial externo. Embora MEDEIROS et al. (1997) tenham empregado procedimento similar no tratamento de fimose em equinos os autores não fizeram referencia a técnica de circuncisão e a sua divisão em tempos operatórios, conforme metodologia descrita no presente estudo.

O exame clínico do tecido epitelial de revestimento peniano realizado logo após a exposição manual do pênis revelou que apenas dois equinos (10\%) apresentaram lesões como fibrose e úlceras nessa estrutura anatômica. A integridade desse folheto foi importante durante o trans-operatório e pode ter contribuído para o sucesso dos procedimentos cirúrgicos.

A sutura em padrão simples separado empregando fio de náilon e utilizada para fixar o tecido sub-eptelial da porção livre do pênis ao tecido localizado sobre a face interna do folheto prepucial externo (Figura 1-C), foi fundamental para manter o órgão na posição correta, evitando-se a sua retração e, conseqüentemente, o recrudescimento do processo. Essa manobra difere da técnica descrita por SILVA et al. (1995), pois esses autores não descolaram e 
removeram a lâmina interna da prega prepucial externa, limitando-se a aproximar e suturar as bordas incisadas do tecido epitelial de revestimento peniano sem, contudo, promover a fixação da porção livre do corpo peniano. No estudo aqui realizado, esta manobra representou a principal modificação da técnica original de circuncisão com encurtamento do pênis recomendada por TURNER \& MCILWRAITH, (1985) e SILVA et al. (1995).

As quatro incisões longitudinais praticadas nas bordas da porção caudal do tecido epitelial de revestimento remanescente, na região da glande (Figura 1-B), imprimiram ao tecido um formato semelhante a pétalas de rosas, permitindo melhor aproximação, justaposição e aplicação das suturas durante a reconstituição dos planos anatômicos incisados, situação que resultou em menor tensão no local, minimizando possivelmente, a ocorrência de deiscências de sutura, pois em apenas dois casos (10\%) essa intercorrência foi completa. De igual forma os pontos de Donatti aplicados após praticar as incisões longitudinais no tecido epitelial de revestimento auxiliaram de forma decisiva na sustentação da ferida cirúrgica, pois em apenas três (15\%) animais ocorreu deiscência parcial de sutura e, nesses casos esses pontos não se romperam. Portanto é possível inferir que tanto as incisões longitudinais realizadas no tecido epitelial de revestimento como a sutura de Donatti foram importantes na manutenção do posicionamento das estruturas anatômicas abordadas. Conforme apontado por SILVA et al. (1995), os pontos de fixação resultam em menor possibilidade de isquemia das bordas do tecido epitelial de revestimento e, conseqüentemente, proporciona menor índice de deiscências. TURNER \& MCILWRAITH (1985) não fizeram referência ao assunto e SILVA et al. (1998) recomendaram fixar a mucosa prepucial, empregando quatro pontos de Donatti no trans-operatório de acropostite-fimose em touros e afirmaram que a técnica diminuiu o comprometimento circulatório local, daí a opção por essa conduta nos animais do presente estudo.

A redução do espaço morto por meio dos pontos separados, aplicados também com a finalidade de aproximar a porção livre do corpo peniano à face interna do prepúcio, iniciando-se na porção mais cranial e estendendo até a região do óstio neoformado, foi fundamental para diminuir o acumulo de seroma no pós-operatório. Apesar da ação benéfica desses pontos, o edema esteve presente, em graus variados, em todos (100\%) os animais, mas reduziu gradativamente a partir do sétimo dia do pós-operatório em 15 (75\%) equinos. Segundo relatos de LITTLE \& HOLYOAK (1992), a formação de edema no pode ser explicado em parte pela sua capacidade de acumular líquido intersticial.

O edema foi classificado como intenso em apenas cinco (25\%) animais nos quais ocorreu deiscência da ferida cirúrgica. Nesses, também foi evidenciada a presença de exudato purulento sugerindo a presença de infecção, sendo necessário aplicar três doses adicionais do antibiótico e realizar a higienização diária da ferida com uma solução de hipoclorito de sódio a 0,5\%. Após tratar a infecção os animais foram submetidos a uma reintervenção cirúrgica, empregando-se a mesma técnica antes que ocorresse o recrudescimento do problema. SILVA et al. (2002), relacionaram essas mesmas complicações a higiene deficiente das instalações e falhas na condução do pós-operatório, especialmente porque esta etapa, geralmente, fica sob a responsabilidade da mão-de-obra auxiliar das propriedades rurais.

A cicatrização clínica se completou em aproximadamente 21 dias, exceto nos animais, nos quais ocorreu deiscência parcial de ferida, sendo necessário prosseguir com os curativos até os 35 dias de pósoperatório, ocasião que ocorreram as reintervenções nos animais que tiveram deiscência total de ferida. Nesses, a recuperação completa ocorreu em aproximadamente dois meses. Segundo BERTONE (1989), fatores locais como contaminação, presença de corpos estranhos à ferida e fatores sistêmicos como as hipovitaminoses e deficiências minerais podem retardar o processo de cicatrização, justificando, em parte, os achados desse estudo.

Mesmo adotando todos os cuidados, pré, trans e pós-operatórios, como o uso de soro antitetânico, emprego de instrumental esterelizado, aplicação de antibiótico à base de penicilina e realização de curativos diários da ferida cirúrgica, ocorreu um (10\%) óbito no $13^{\circ}$ dia do pós-operatório, dentre os equinos que compuseram o grupo GI, após o diagnóstico de tétano. Provavelmente essa complicação esteve relacionada ao ambiente favorável que a genitália de equinos propicia para o desenvolvimento de bactérias anaeróbias, como o Clostridium tetani, e a contaminação por sujidades contendo esse agente microbiano. Acrescente-se ainda a possibilidade de falha na condução do pós-operatório como apontado por SILVA et al. (2002).

Finalizando, pela retenção urinária observada em 16 (80\%) equinos que constituíram os diferentes grupos submetidos ao tratamento cirúrgico, deduz-se que havia grande contaminação local. Portanto, esperava-se que seria encontrado maior numero de complicações durante a condução do pósoperatório. Ao contrário, apesar da demora em se 
proceder ao tratamento cirúrgico e a dificuldade na condução do pós-operatório em alguns criatórios atendidos, o número de casos recuperados indica que a modificação realizada na técnica original de circuncisão com encurtamento do pênis constitui-se em alternativa viável no tratamento de fimose traumática em equinos.

\section{CONCLUSÕES}

Fatores como injúria tecidual peniana e prepucial associados à ausência de tratamento ou o emprego de tratamentos inapropriados podem ter propiciado o desenvolvimento de fimose nos equinos desse estudo. A técnica de circuncisão com encurtamento do pênis com as modificações propostas neste estudo mostrou ser uma alternativa eficiente para a correção desta enfermidade. Óbitos ocorreram quando o tratamento foi inadequado e devido intercorrências pós-operatórias.

\section{REFERÊNCIAS}

BERTONE, A.L. Second-intention healing. Veterinary Clinics of North America: Equine Practice, Philadelphia, v.5, n.3, p.234-239, 1989.

CERVENY, C. et al. Orgãos genitais masculinos. In: KONIG, H.E.; LIEBICH, H.G. Anatomia dos animais domésticos. Porto Alegre: Artmed, 2004. 2v, p.137-154.

GATEWOOD, D.M. et al. Diagnosis and treatment of acquired pathologic conditions of the equine penis and prepuce. Compendium on Continuing Education for the Practicing Veterinarian, Yardley, v.11, n.12, p.1498-1504, 1989.

LITTLE, T.V.; HOLYOAK, G.R. Reproductive anatomy and physiology of the stallion. Veterinary Clinics of North America: Equine Practice, Philadelphia v.8, n.1, p.1-29, 1992.

MAIR, T.S. et al. Surgical treatment of 45 horses affected by squamous cell carcinoma of the penis and prepuce. Equine Veterinary Journal, London, v.32, n.5, p.406-410, 2000. Disponível em:<http:dx.doi.org/10.2746/042516400777591093>. Acesso em 09 jul. 2009. doi: 10.2746/042516400777591093.
MACKINNON, A.O.; VOSS, J.L. Equine reproduction. Philadelphia: Lea \& Febiger, 1992. 462p.

MEDEIROS, A.A. et al. Correção cirúrgica de fimose adquirida em equinos. Veterinária Notícias, Uberlândia, v.2, n.1, p.4349, 1997.

MEMON, M.A et al. Preputial hematoma in a stallion. Journal of American Veterinary Medical Association, Philadelphia, v.191, n.5, p.563-564, 1987.

PAPA, F.O.; LEME, D.M. Testicular fine needle aspiration cytology with testicular degeneration after external genitalia trauma. Journal of Equine Veterinary Science, New York, v.22, p.121-124, 2002. Disponível em: <http://dx.doi.org/ 10.1016/S0737-0806(02)70124-X>. Acesso em 09 jul. 2009. doi: 10.1016/S0737-0806(02)70124-X.

PERKINS, N.R.; FRAZER, G.S. Reproductive emergencies in the stallion. Veterinary Clinics of North America: Equine Practice, Philadelphia, v.10, n.3, p.671-683, 1994.

SAMPAIO, B.M. Estatística aplicada à experimentação animal. Belo Horizonte: FEPMVZ, 2002. 221p.

SCHUMACHER, J.; VAUGHEN, J.T. Surgery of penis and prepuce. Veterinary Clinics of North America: Equine Practice, Philadelphia, v.4, n.3, p.473-491, 1988.

SILVA L. A.F. et al. Técnica de circuncisão com encurtamento do pênis para obtenção de rufiões equinos. Arquivo Brasileiro de Medicina Veterinária e Zootecnia, Belo Horizonte, v.47, n.6, p.789-798, 1995.

SILVA, L.A.F. et al. Tratamento cirúrgico da estenose e/ou fibrose prepucial em touros. ARS Veterinária, Jaboticabal, v.14, n.2, p.235-244, 1998.

SILVA L. A.F. et al. Complicações decorrentes da utilização da acepromazina associada à xilazina na preparação cirúrgica de rufiões bovinos. Ciência Rural, Santa Maria, v.32, n.3, p.439444, 2002. Disponível em: <http://dx.doi.org/10.1590/S0103$84782002000300012>$. Acesso em 09 jul. 2009. doi: 10.1590/ S0103-84782002000300012.

TURNER, A.S.; MCILWRAITH, G.W. Técnicas cirúrgicas em animais de grande porte. São Paulo: Roca, 1985. 354p.

WALDRIDGE, B. M., GILLIS, J.P. Surgical treatment of redundant preputial tissue in a gelding. Equine Practice, Philadelphia, v.18, n.4, p.12-14, 1996. 